agriculture, where it is more static. Neither theory is entirely satisfactory; arguments can be advanced against both. On the whole, in Mr. Macey's opinion, the former is to be preferred. It gives the more logical interpretation of rheological properties. Shear hardening, for example, is due to rearrangement of the particles into systems of smaller potential energy. Plastic clay is outstanding in that the greater the rate of shear, the greater the deformation before failure; and this can be explained by the hysteresis which is known to exist in the change of moisture-content with applied pressure between porous pistons. Differences in plastic properties become associated with differences in particle size, distribution and packing.

Pictures were shown of drying cracks in extruded bricks and other ceramic materials, and illustrations given of the very great increase in plasticity or deformation before rupture which can be obtained in some clays by removing occluded air.

In the following discussion Dr. G. Scott-Blair referred to earlier work on the effect of de-airing wet clay slips. Dr. L. N. O. Clark suggested that it might be possible to throw some light on the question of honeycomb structure by following a procedure worked out for the preparation of light magnesium oxide. In this a gel in water is taken at high pressure above the critical temperature, the water removed as gas and the solid but tenuous structure cooled. The liquid water is thus removed without a phase change, and the most delicate structure can be preserved.

If the structure were held by electrical forces one would expect a relationship between its strength with the dielectric constant of the medium.

Dr. Emödi gave arguments in favour of the honeycomb theory; but some of these arguments applied, as Dr. Treloar pointed out, to more dilute systems than to the plastic state.

G. N.

\section{SELECTION FOR MANAGEMENT}

$\mathrm{T}$ HE discussion on selection for management arranged by Section J (Psychology) of the British Association on August 29 fully conformed to the general theme of the Dundee meeting suggested by the Council of the Association. Essentially this discussion considered the methods of officer selection developed by the Services during the War, and the way in which the principles of such methods and the experience gained in using them, rather than the exact methods themselves, could be applied to the problem of selection for management. The magnitude of this problem has been emphasized in the recent Urwick Report on Education for Management. On the assumptions of that Report, some twelve thousand recruits are required annually to maintain the supply of half a million or so managers ; this obviously demands all the help which the comparatively small number of psychologists can afford.

Dr. T. Ferguson Rodger's admirable paper gave a very clear account of the development of methods of officer selection with which he was associated in the Army, and two of the six reasons he gave for the introduction of new techniques of selection in 1941 may have some bearing on the selection of managers. In industry as in O.T.C. units, morale may be affected by a high rate of rejection of candidates; while, just as in the Army the wide- spread dissatisfaction with the system of short inter. views by a small board of senior officers made it important to seek a method that would ensure that justice was manifestly done, so in industry it is no less important from the point of view of production and incentives that the selection of men for management should be quite free from favouritism or nepotism. Dr. Rodger emphasized here the necessity of paying attention to the attitudes and prejudices which are expressive of the cultural traditions of the institution or industry, and for this very reason the methods most effective for a particular Service such as the Army cannot be rigidly applied to another institution or another Service.

With this warning Dr. Rodger described the methods ultimately adopted, bringing out clearly the way in which the technical officers, such as psychologists and psychiatrists, who were members of the selection boards, were used to produce the information in such a form that it could be weighed by others. Dr. Rodger directed particular attention to the importance of group discussion and of the principle of the leaderless group in which a candidate might prove his ability to lead by actually taking command of a situation by common consent.

If Dr. Rodger indicated some of the limitations of the exact methods of selection used in the Army, Mr. A. Rodger brought out some further points which need to be considered in applying such experience in the field of industry or business. Emphasizing the fact that improvement of occupational selection does not necessarily involve the use of elaborate modern techniques of assessment, he pointed out that the chief requirement is a reasonably clear notion of what we are trying to assess. The first question to be answered is, "What are we looking for in these candidates ?" This would not be answered merely by composing lists of 'qualities' desired. It is usually more profitable to compile lists of 'situations' which have to be handled in the occupation under review, and to consider each candidate's probable effectiveness in them in the light of relevant evidence collected from every available source.

The process of selection, moreover, said Mr. Rodger, should not be divorced from that of recruitment; failure to throw up suitable candidates for promotion might well be due to failure to secure initially recruits of the proper quality. Again, if the psychologist is to assist in the selection of men for management, he must have more than superficial knowledge of the nature of the duties the candidate would be expected to perform. Ho must be fully informed not only about the general nature of such duties but more specifically of what may be termed the danger spots, or those situations in which trouble or difficulty in a particular occupation is specially liable to arise. A good selector is not himself necessarily a good manager or administrator, but knowledge of such problems or situations is far more important than lists of necessary qualities in judging the probable effectiveness of a candidate. Mr. Rodger also referred to the value of group discussions among candidates themselves and, in urging that the interview should be troated seriously, observed that the important questions are not thosewhich the selection board asks the candidate, but those that the members of the board would afterwards ask thernselves about the candidate.

These two papers put the whole discussion on a firm practical basis, and in themselves showed how large a contribution psychology could make in this 
important problem. There were no large claims : the responsibility for selection must lie fairly on the shoulders of the employer. But by dispelling false ideas as to the necessity of elaborate techniques, the discussion showed how the psychologist could clarify ideas and simplify the process; thereby assisting in making the selection process acceptable to all concerned, because it filled the proviso that was allimportant in the field of officer selection during the War-that so far as possible justice was done.

\section{AMERICAN AWARDS TO BRITISH MEN OF SCIENCE}

$\mathrm{T}$ Nature of May 17, p. 684, a list was given of 1 awards of the Medal of Merit, the highest award made by the Government of the United States to a civilian, to eight leading men of science in Britain, for services during the War. Recently thirty-two other British subjects received decorations for their work; the list includes the following names of scientific men, with a brief statement indicating the grounds of the award:

\section{Medal of Freedom, with Silver Palm}

Dr. H. J. Gough, director-general of scientific research and development in the Ministry of Supply;

Prof. A. V. Hill, for exceptionally meritorious service in the field of scientific research and development ;

Sir Frank Smith, controller of telecommunications equipment in the Ministry of Aircraft Production and chairman of the Scientific Advisory Council of Ministry of Supply ;

Dr. R. L. Smith-Rose, for scientific investigations which laid the groundwork for important developments in the field of radio propagation.

\section{Medal of Freedom, with Bronze Palm}

Prof. J. D. Bernal (University of London), for meritorious service in the field of scientific research and development; and in assessing bomb damage;

Dr. Henry G. Booker (University of Cambridge), head of the Mathematics Section at the Telecommunications Research Establishment of the Ministry of Aireraft Production ;

Mr. A. Lang Brown, Department of Scientific Research and Experiments (Admiralty), and secretary of the Admiralty Committee on Infra-Red Research ;

Mr. S. J. Grose (Ministry of Supply), secretary of the British Counter Measures Board;

Dr. Hubert G. Hopkins (Radio Division, National Physical Laboratory), for meritorious service in the field of scientific research and development, working in the field of radio ;

Dr. E. Talbot Paris, physicist in the Ministry of Supply, responsible for development of radar communications and other electronic equipment;

Dr. William J. Richards (Telecommunications Research Establishment), deputy director of scientific research in the Ministry of Aircraft Production, concerned with aerial warfare and guided missiles;

Mr. William Ross, for meritorious service as physicist in the field of radio and radar;

Mr. John M. C. Scott, physicist working on radio propagation, member of the Radar Research Development Establishment and secretary of the Ultra-Short Wave Propagation Panel of the Ministry of Supply.

\section{Medal of Freedom}

Mr. W. G. Busbridge (Chemical Defence Experimental Station, Porton, Wilts), for meritorious service in the field of scientific development, chemical warfare ;

Mr. W. J. Challens (Ministry of Supply), for important comprehensive investigations in relation to rockets ;

Prof. C. N. Hinshelwood (University of Oxford), for meritorious service in the field of scientific development and for successful research in gas-mask absorbents.

\section{Bronze Star Medal}

Captain B. R. S. Dalton, in charge of orientation and training in photo interpretation, Photo Intelligence Centre, Military Intelligence Service, December 1943-June 1944 ;

Lieut.-Colonel H. F. Jones, for his work on the basic investigation and planning for new types of fuels for use in the British Army, September 1942May 1945.

Medal for Merit

Dr. R. V. Jones (Department of Natural Philosophy, University of Aberdeen), for outstanding service to the United Nations during 1939-45; assistant director of intelligence (science) at the British Air Ministry.

\section{THE FACTUAL FILM}

$T$ $\mathrm{HE}$ second of four reports to be presented by the Dartington Hall Trustees on the Visual Arts, the Factual Film, Music and the Theatre has recently been published*. The work of the Arts Enquiry, which was established in 1941, the reports are designed to give an account of the place of these arts in the national life, their economic and administrative background, their social importance and their value in general education. As the statement that "the documentary is Britain's outstanding contribution to the film" may be regarded as one of fact rather than of opinion, it is only right that a study of the British documentary film should have been included in this series.

Important as are the historical sections-and more especially those which trace the early development of documentary films under the direction of John Grierson at the Empire Marketing Board and the General Post Office, the effect of war-time demands for films for training purposes, and the evolution of the educational film - chief interest centres around the comments, criticisms and recommendations which the authors have incorporated. The work of the Film Division of the Ministry of Information and the film activities of the British Council are assessed. The trivial content of many news-reels is criticized. The case for a more systematic preservation of films for record purposes is presented. The necessity for the training of teachers in the use of films is stressed. The activities of the British Film Institute are held to be unsatisfactory on account of weaknesses in its constitution, organisation and methods of finance"though these cannot be held wholly responsible for the lack of initiative and drive characteristic of much of its work".

It says much for both the foresight and insight of those responsible for this report that three of the four

* The Factual Film: a Report published on behalf of the Arts Enquiry by P.E.P. (Political and Economic Planning) Pp. 260. (Oxford University Press ; Geoffrey Cumberlege, 1947.) 128. $6 d$. net. 